\title{
CMT ve Darbeli CMT Ark Kaynaklı AA7075-T6 Al- Alaşımı Alın Bağlantıların Mekanik Davranışına Kaynak Hatalarının Etkisinin Araştırılması
}

\author{
H. Tarık SERİNDA $\breve{G}^{1 *}$, Gürel ÇAM ${ }^{2}$ \\ Geliş / Received: 03/12/2019 \\ Revize / Revised: 06/01/2020 \\ Kabul / Accepted: 27/02/2020
}

ÖZ

Al-alaşımları hafiflik, iyi korozyon performansı, iyi şekillendirilebilirlik ve yüksek mukavemet gibi oldukça iyi bir mekanik özellik kombinasyonuna sahiptir. Bunun sonucu, özellikle de hafiflik istenen taşımacılık sanayi başta olmak üzere birçok alanda yaygın olarak kullanılmaktadırlar. Ancak, bu alaşımların, özellikle de yaşlandırma sertleşmesi yapılmış AA7075-T6 gibi yüksek mukavemetli olan türlerinin, ergitme kaynağında porozite oluşumu, çatlama ve kaynak bölgesinde aşırı mukavemet kaybı gibi problemlerle karşılaşılmaktadır. Dolayısıyla, bu alaşımların başarılı bir şekilde kaynaklanabilir olması endüstride daha da yaygın olarak kullanılmalarını sağlayacaktır. Bu bağlamda, katı hal kaynakları ve soğuk metal transferi (cold metal transfer CMT) gaz metal ark kaynağı (GMAK) veya lazer kaynağı gibi düşük 1sı girdili ergitme kaynakları ümit vadetmektedir.

$\mathrm{Bu}$ çalışmanın amacı, soğuk metal transferi (CMT) ark kaynağı tekniği kullanılarak kaynak edilen AA7075-T6 levhaların kaynak dikişinde porozite oluşumu ve oluşan porozitenin kaynaklı levhanın mekanik özelliklerine etkisinin incelenmesidir. Bu çerçevede, 2 mm kalınlığındaki AA7075-T6 Al-alaşımı levhalar hem geleneksel CMT hem de darbeli CMT ark kaynağı yöntemleri kullanılarak birleştirilmiştir. Kaynaklı levhaların içyapıları ve mekanik özellikleri detaylı optik mikroskop çalışmaları, mikrosertlik ölçümleri ve çekme deneyi ile incelenmiştir. Ayrıca, kaynak dikişinde oluşan iri porozitelerin kaynaklı levhanın mekanik davranışına etkisini belirlemek için porozite oluşumu ile kaynak performansı arasında bir ilişki kurulmaya çalışılmıştır.

Anahtar Kelimeler- Al-alaşımı, AA7075, Soğuk metal transfer (CMT) ark kaynă̆ı, Porozite oluşumu, Kırılma davranışı.

\footnotetext{
1*Sorumlu yazar iletișim: htarik.serindag@iste.edu.tr (https://orcid.org/0000-0003-3864-8147)

Makine Mühendisliği Bölümü, İskenderun Teknik Üniversitesi, Merkez Kampüs 31200 İskenderun-HATAY

2İletişim: gurel.cam@iste.edu.tr (https://orcid.org/0000-0003-0222-9274)

Makine Mühendisliği Bölümü, İskenderun Teknik Üniversitesi, Merkez Kampüs 31200 İskenderun-HATAY
} 


\title{
Investigation of the Influence of Weld Defects on the Mechanical Behavior of Cold Metal Transfer (CMT) and Cold Metal Transfer Pulsed (CMT-Pulsed) Arc Welded AA7075-T6 Al-Alloy Butt Joints
}

\begin{abstract}
Al-alloys possess a very good combination of mechanical properties such as lightweight, good corrosion performance, good formability and high strength. Thus, they are widely employed in several industries, particularly in transport industry, where lightweight is required. However, fusion joining of these alloys, particularly age hardened grades such as AA7075-T6, involve several difficulties such as porosity formation, cracking and loss of strength in the weld area. Thus, successful joining of these alloys will further increase their use in industrial applications. In this respect, solid state joining or fusion welding techniques with low heat input such as cold metal transfer (CMT) gas metal arc welding (GMAW) technique or laser beam welding are promising joining methods.
\end{abstract}

This study aims at investigating the formation of weld defects (i.e., pores) and determining the effect of pores on mechanical performance of the AA7075-T6 plate joints produced using CMT arc welding technique. For this purpose, AA7075-T6 Al-alloy plates with a thickness of $2 \mathrm{~mm}$ were joined using both conventional CMT and CMT pulse arc welding techniques. The microstructural and mechanical properties of the welded plates were investigated by detailed optical microscopy investigations, micro-hardness measurements and tensile tests. Moreover, a correlation between the joint performance and the formation of porosity in the fusion zone (FZ) was also attempted to show the effect of the presence of large pores on the mechanical behavior of the joint.

Keywords-Al-alloy, AA7075, Cold metal transfer (CMT) arc welding, Porosity formation, Fracture behavior. 


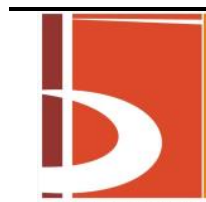

BŞEÜ Fen Bilimleri Dergisi

7. Cilt - Milli Mücadele ve TBMM'nin

Açılıșının 100. Yılı Anısına-100. Yıl Özel

Say1s1

243-255, 2020
BSEU Journal of Science

DOI: $10.35193 /$ bseufbd. 654456

e-ISSN: $2458-7575$ (http://dergipark.gov.tr/bseufbd)

\section{GİRIŞ}

Al-alaşımları, mükemmel spesifik mukavemet ve kırılma özellikleri, kolay şekil verilebilirlik ve iyi korozyon dirençlerinden dolayı, günümüzde taşımacılık sektöründe, özellikle de hafiflik gerektiren uygulamalarda yaygın olarak kullanılmaktadır [1]. Alüminyum alaşımları içerisinde yaşlandırma sertleştirmesi yapılmış AA7075 Al-alaşımı (T6 temper durumunda) çeliklere yakın yüksek bir mukavemet değerine sahip bir alaşımdır [2]. Bir malzemenin ticari olarak yaygın olarak kullanımı o malzemenin kaynaklanabilirliğine bağlıdır. Ancak, Al-alaşımlarının - özellikle de yüksek mukavemetli yaşlandırılmış alaşımların - geleneksel ergitme kaynaklarında elektron ışını kaynağı dışındaki tüm ergitme kaynaklarında sorun olan porozite oluşumu yanında katılaşma çatlakları ve kaynak bölgesinde aşırı mukavemet kaybı gibi sorunlarla karşılaşılmaktadır [2-7]. Özellikle de, AA7075-T6 alaşımının ergitme kaynağı problemlidir, hatta ergitme kaynağı yapılamaz diye nitelendirilmektedir. Bu problemlerin ana nedeni ergitme kaynaklarında malzemenin maruz kaldığı yüksek 1s1 girdisidir. Dolayısıyla, bu sorunların giderilmesi için bir yaklaşım doğaları gereği düşük ısı girdisinin söz konusu olduğu, sürtünme karıştırma kaynağı (SKK) gibi katı hal kaynak yöntemlerini kullanmaktır. Nitekim son 30 yıl içerisinde Al-alaşımları [2,3,8-20], saf kurşun [21], Cu-alaşımları [22], Mg-alaşımları [23] ve çelikler gibi yüksek ergime dereceli yapı malzemelerinin [24-27], SKK yöntemiyle birleştirilebilirliği konusunda çok sayıda çalışma gerçekleş̧irilmiştir. Katılaşma sırasında meydana gelen çatlakları ve kaynak bölgesindeki mukavemet kaybını önlemek için alınabilecek ikinci önlem düşük 1sı girdili ergitme kaynaklarının kullanılmasıdır. Örneğin, Fronius firması tarafından 2004 yılında Avusturya'da geliştirilen gaz metal ark kaynağının (GMAK) bir versiyonu olan soğuk metal transferi (CMT) ark kaynağı, kaynak esnasında veya sonrasında çatlamanın söz konusu olduğu Al-alaşımları gibi malzemelerin kaynağında bir avantaj sunmaktadır [28,29]. Soğuk kaynak olarak adlandırılan bu yöntem, kaynak dikişinin görünümünü iyileştirmek ve düşük bir 1sı girdisi ile kontrollü bir biçimde kaynak bölgesine metal transferi gerçekleştirmek amacıyla geliştirilen kısa devre temelli bir kaynak tekniğidir. Bu yöntemde, GMAK yönteminden farklı olarak kısa aralıklarla arklar oluşturularak daha düşük 1sı girdisi ve hızlı dijital işlem ünitesi ile desteklenmiş yenilikçi bir ilave tel besleme sistemi ile de proses parametrelerini daha iyi şekilde kontrol edilebilirliği durumundan dolayı da çok daha iyi bir kaynak performansı elde edilebilmektedir [27]. Darbeli-CMT kaynağı yöntemi ise, CMT kaynağı ile darbeli arkın birleşimi ile ortaya çıkan diğer bir CMT kaynak versiyonudur. Bu versiyonda, CMT kaynak döngüsünün ark fazı sırasında darbeli akım uygulanır. Bu sayede kaynak bölgesine daha fazla 1sı girdisi verilir. Böylece, hem daha fazla metal transferi hem de daha fazla nüfuziyet meydana gelir. Bu yöntemde, kaynak bölgesine olan metal transferi damlacık şeklinde gerçekleşir. Kaynak döngüsünün ark fazı sırasında daha yüksek akım uygulanacaksa (tepe akım ve/veya uygulanan akım süresi), kontrolsüz damlacık ayrılmasına neden olabilir. Bu sorunun önüne geçmek için damlacık ayrılmasının kontrollü bir şekilde gerçekleştiği CMT ark fazına akım darbeleri uygulamaktır. Yani kaynak arkı boyunca darbe başına kaynak dikişine bir damlacık transfer edilir [28]. Ayrıca, soğuk metal transferi (CMT) ark kaynağı yönteminin geleneksel CMT, darbeli CMT, ileri CMT ve ileri darbeli CMT olmak üzere değişik varyasyonları da bulunmaktadır [30].

Literatürde, Al-alaşımlarının CMT ark kaynağı konusunda son yıllarda yürütülen çok sayıda çalışma bulunmakta iken [28-32], ancak AA7075 Al-alaşımının CMT ark kaynağı üzerine çok az sayıda çalışma söz konusudur [33]. Dolayısıyla, bu alaşımın CMT ark kaynağı yöntemiyle kaynak edilebilirliğinin tam olarak anlaşılabilmesi için bu konuda daha fazla araştırma yapılmasına gereksinim bulunmaktadır. Bu çalışmanın motivasyonu da budur. Bu çalışmanın amacı, hem CMT hem de darbeli CMT ark kaynağı yöntemleri ile AA7075 Al-alaşımında hatasız kaynak elde edilme potansiyelini belirlemektir. Bu amaçla, $2 \mathrm{~mm}$ kalınlığındaki AA7075-T6 Al-alaşımı levhalar her iki ark kaynağı yöntemi kullanılarak birleştirilmişlerdir. Elde edilen kaynaklı alın birleştirmelerin içyapıları ve mekanik özelliklerini incelemek için detaylı optik mikroskop çalışmaları, mikrosertlik ölçümleri ve çekme deneyleri yapılmıştır. Ayrıca, kaynak performansı ile porozite oluşumu ilişkisini açıklayabilmek için de kırılmış çekme numuneleri üzerinde detaylı optik mikroskop incelemeleri yapılmıştır. 


\section{DENEYSEL ÇALIŞMALAR}

Bu çalışmada, 2 mm kalınlığında AA7075-T6 plakalar kullanılmıştır. Robotik geleneksel CMT kaynak yöntemi ve darbeli CMT ark kaynağı tekniği kullanılarak kaynak işlemlerini gerçekleştirmek için baz malzemeden $245 \times 150 \times 2 \mathrm{~mm}^{3}$ ölçülerinde deney numuneleri çıkarılmıştır. Numunelerde, kaynak yapılacak yüzeyler kaynak öncesi metal bir firça ile temizlemiştir. Kaynaklanacak yüzeylere başka bir temizleme işlemi uygulanmamıştır. Kaynak işleminde, $1.2 \mathrm{~mm}$ çapında ER5356 besleyici tel kullanılmıştır. Kaynak işlemi için kullanılan parametreler Tablo 1'de verilmiştir. Tüm kaynak işlemlerinde, argon koruyucu gaz ark oluşturulduktan $0.1 \mathrm{~s}$ önce beslenmeye başlanmış ve kaynak işlemi tamamlandıktan $0.5 \mathrm{~s}$ sonra kesilmiştir.

Tablo 1. Kaynak işlemlerinde kullanılan kaynak parametreleri.

\begin{tabular}{cccccc}
\hline Kaynak işlemi & $\begin{array}{c}\text { Akım } \\
(\mathbf{A})\end{array}$ & Gerilim (V) & $\begin{array}{c}\text { Kaynak hızı } \\
(\mathbf{m m} / \mathbf{d a k})\end{array}$ & $\begin{array}{c}\text { Tel besleme hızı } \\
(\mathbf{m} / \mathbf{d a k})\end{array}$ & $\begin{array}{c}\text { Koruma gazı debisi } \\
(\mathbf{l} / \mathbf{d a k})\end{array}$ \\
\hline Robotik CMT & 120 & 15.2 & 900 & 11 & 15 \\
\hline Darbeli CMT* & 103 & 18.3 & 900 & 8.3 & 15 \\
\hline \multicolumn{7}{c}{$*$ darbeli ark (puls) akım 90 amper ile 120 amper aralığında değiştirilerek oluşturulmuştur. }
\end{tabular}

Kaynak bölgelerindeki mikroyapı ve sertlik değişimlerini değerlendirmek ve çekme dayanımı ve benzeri mekanik özellikler ile kaynaklı bağlantıların kaynak performans değerlerini belirleyebilmek için kaynağı yapılmış her bir kaynaklı levhadan, bir tane metalografi numunesi ve 4 tane de çekme testi numunesi çıkarılmıştır. Metalografi numuneleri zımparalanmış ve sonrasında parlatılmıştır ve sonrasında da içyapı incelemeleri ve mikrosertlik ölçümleri yapabilmek için Keller ayracı $(150 \mathrm{ml} \mathrm{saf} \mathrm{su,} 3 \mathrm{ml} \mathrm{HNO3,} 6 \mathrm{ml} \mathrm{HCI}$ ve 6 $\mathrm{ml} \mathrm{HF}$ ) kullanılarak $120 \mathrm{~s}$ süresince dağlama işlemi gerçekleştirilmiştir. Yapılan kaynak işlemleri sonunda çıkarılan metalografi numunelerinin kaynak bölgelerinde (Ergime Bölgesi ve Isıdan Etkilenen Bölge) kesit alanı boyunca içyapı değişimlerini ve bu bölgelerde meydana gelen porozite oluşumunu değerlendirmek için detaylı bir optik mikroskop çalışması yapılmıştır. Kaynaklı birleştirmelerin sertlik dağılımlarını belirlemek için her bir kaynaklı bağlantının kaynak bölgesinin kesit alanı boyunca malzemenin kalınlı̆̆ının ortasına denk gelecek bir çizgi boyunca birçok noktada $200 \mathrm{~g}$ ağırlık kullanılarak Vickers mikro sertlik ölçümleri $\left(\mathrm{HV}_{0.2}\right)$ gerçekleştirilmiştir. Standart enine çekme testi numuneleri hem baz malzemeden hem de kaynaklanmış olan plakalardan çıkarılarak $0.1 \mathrm{~mm} / \mathrm{dak}$ çekme hızı kullanılarak çekme testleri gerçekleştirilmiştir. Bunlara ek olarak, çekme testinden sonra kırılmış numunelerden hazırlanmış metalografi numuneleri üzerinde de, kaynak bölgesinin mekanik özellikleri ile içyapıdaki değişimler arasında bir bağlantı kurabilmek ve çekme deneyi sonucunda kaynaklı numunelerin kırılma modlarını belirlemek için, detaylı bir optik mikroskop çalışması yapılmıştır.

\section{DENEYSEL BULGULAR VE TARTIRŞMA}

\section{Mikroyapr}

Geleneksel ve darbeli CMT kaynak yöntemleri kullanılarak bu çalışma kapsamında yapılmış olan kaynaklı birleştirmelerden elde edilmiş olan makro resimler Şekil 1'de verilmiştir. Bu resimde görüleceği üzere, her iki kaynaklı birleştirmede de herhangi bir çatlak gözlenmemiştir. Diğer taraftan, her iki yöntemle elde edilen kaynaklı parçaların ergime bölgesinde nispeten yoğun bir porozite oluşumu söz konusudur. Bu durum, Elrefaey [33] tarafindan rapor edilen ve çok benzer kaynak parametreleri kullanılarak üretilen CMT kaynaklı 7075-T6 bağlantıların ergime bölgesinde çok az miktarda nispeten küçük porozite oluşumunu bildiren sonuçların aksine bir durum ortaya çıkarmıştır. Bununla birlikte, yukarıda belirttiğimiz çalışmada yazarlar, kaynak öncesi yüzeylerin aseton ile temizlendiğini rapor ederken, bu çalışmada sadece metal firça kullanarak mekanik olarak bir temizlik gerçekleştirilmiştir. Bu çalışmada, CMT ve darbeli CMT ile elde edilen kaynaklı bağlantıların ergime bölgelerinde porozite oluşumunun nedeni, birleştirme işleminden önce uygulanan yüzey temizleme prosedürünün yüzeydeki oksit tabakasının ve diğer yüzey kirliliklerinin uzaklaştııılması için yetersiz olmasıdır. Yoğun porozite oluşumu için diğer bir neden de, bu çalışmada yapılan kaynak işlemleri sonrasında soğuma hızının yüksek olması olabilir. 


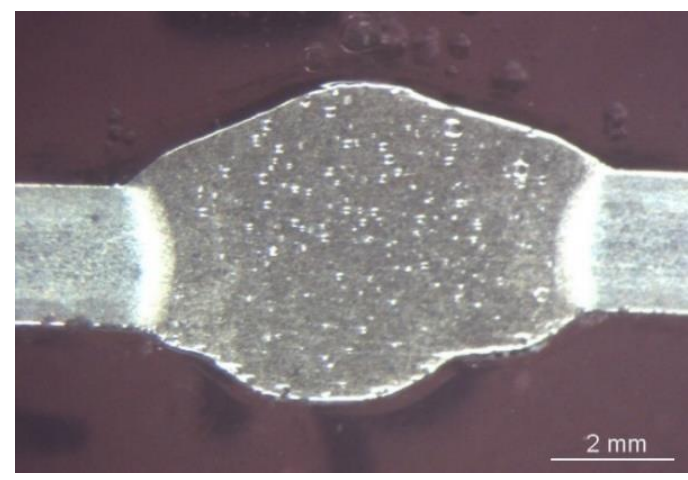

(a)

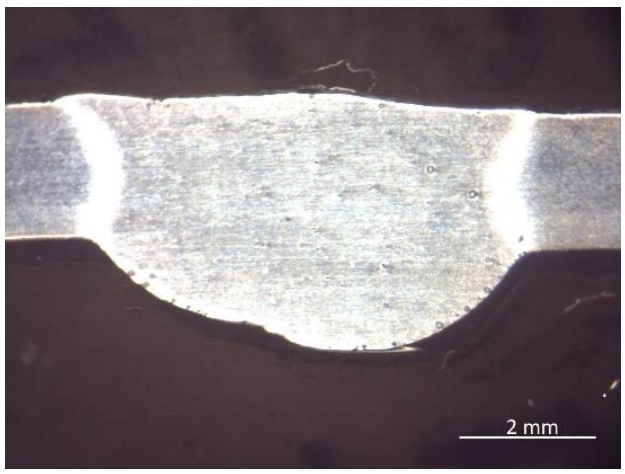

(b)

Şekil 1. Kaynaklı bağlantıların kesitlerini gösteren makro resimler: a) geleneksel CMT ve b) darbeli CMT ark kaynaklı bağlantı.

Bu çalışmada kullanılan AA7075-T6 baz malzemenin içyapısı Şekil 2'de verilmiştir. Bu mikro resimden anlaşılacağı üzere, baz malzeme içyapısı, homojen bir şekilde dağılım göstermeyen demir ve silikon bakımından zengin iri partiküller içeren alfa tanelerinden oluşmaktadır. Daha önce yapılmış olan yayınlarda rapor edildiği üzere [13,16,17], $\mathrm{Al}_{7} \mathrm{Cu}_{2} \mathrm{Fe}, \mathrm{Al}_{12} \mathrm{Fe}_{3} \mathrm{Si}$ ve $\mathrm{Mg}_{2} \mathrm{Si}$ partikülleri, alfa matrisinde gelişi güzel bir biçimde yönlenmişlerdir. AA7075 baz malzemenin içyapısı, ayrıca bu alaşımın T6 temper durumunu alması için yapılan sertleştirme 1sıl işleminin bir sonucu olarak alfa taneleri içerisinde homojen bir biçimde dağılmış çok ince taneli mukavemet artırıcı $\mathrm{MgZn}_{2}$ çökeltilerini de içermektedir. Ancak, bu sert partiküller $\left(\mathrm{MgZn}_{2}\right)$ fazlasıyla ince taneli olduklarından (mikron-altı) optik mikroskop altında ve hatta taramalı elektron mikroskopu altında da görülememektedir.

Şekil 3 ve Şekil 4'den açıkça görüleceği üzere, her iki kaynaklı bağlantının ergime bölgesi de, kaynak işleminden sonra meydana gelen katılaşma sonucu oluşan içinde bazı partiküller içeren dendritik bir yapı sergilemiştir. Ayrıca, daha önce de belirtildiği gibi ergime bölgesinde belirgin miktarda büyük poroziteler açıkça gözlemlenmiştir. Ayrıca yaşlandırma sertleştirilmesi yapılan AA7075-T6 alüminyum alaşımlarının içyapısınında (alfa fazı tanelerinin içerisinde homojen dağılmış çok ince taneli) mukavemet arttırıcı partiküllerin varlığı söz konusudur. Kaynak işlemi esnasında, kaynak bölgesine verilen 1sı girdisi sonucunda, kaynak dikişindeki bu partiküller çözülür ve dendritik bir yapı oluşur, dolayısıyla bu bölgede sertlik düşer. Ayrıca, kaynak dikişinin her iki tarafındaki ısıdan etkilenen bölgelerinde (IEB) bu mukavemet arttırıcı ince taneli partiküller difüzyon yoluyla biraraya gelerek kabalaştığı aşırı yaşlanma gerçekleşir. Ek olarak, IEB'lerde matris fazı olan alfa taneleri de irileşir. Buna paralel olarak da hem çökelti partiküllerinin çözüldüğü kaynak dikişinde hem de tane irileşmesinin (aşırı yaşlanmanın) gerçekleştiği IEB'lerde sertlik düşüşünün meydana geldiği gözlemlenmiştir.

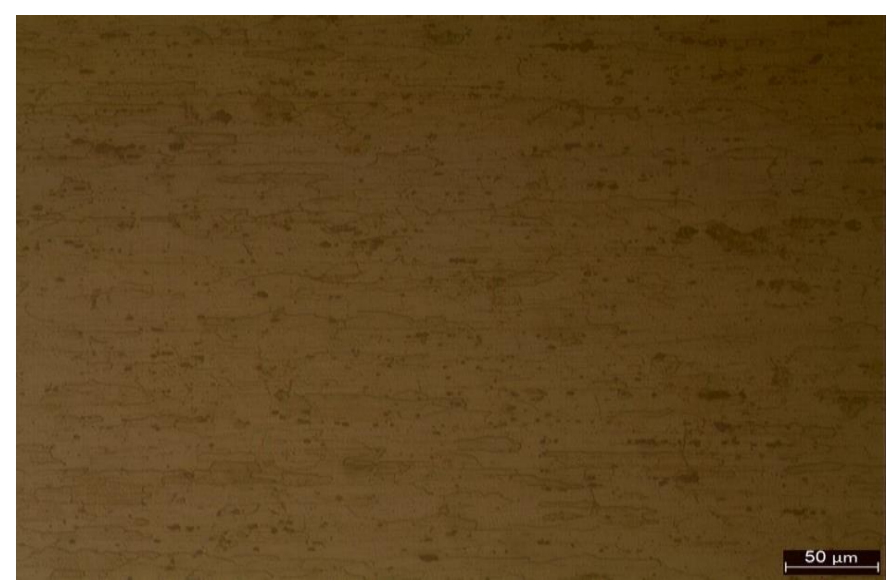

Şekil 2. Baz malzeme içyapısını gösteren mikro resim 


\begin{tabular}{l|lr}
\hline \hline & $\begin{array}{l}\text { BŞEÜ Fen Bilimleri Dergisi } \\
\text { 7. Cilt - Milli Mücadele ve TBMM'nin }\end{array}$ & BSEU Journal of Science \\
Aç1lişının 100. Y1l Anısina-100. Y1l Özel & DOI: 10.35193/bseufbd. 654456 \\
Sayis1 & \\
$243-255,2020$ & \\
& & e-ISSN: 2458-7575 (http://dergipark.gov.tr/bseufbd) \\
\hline
\end{tabular}

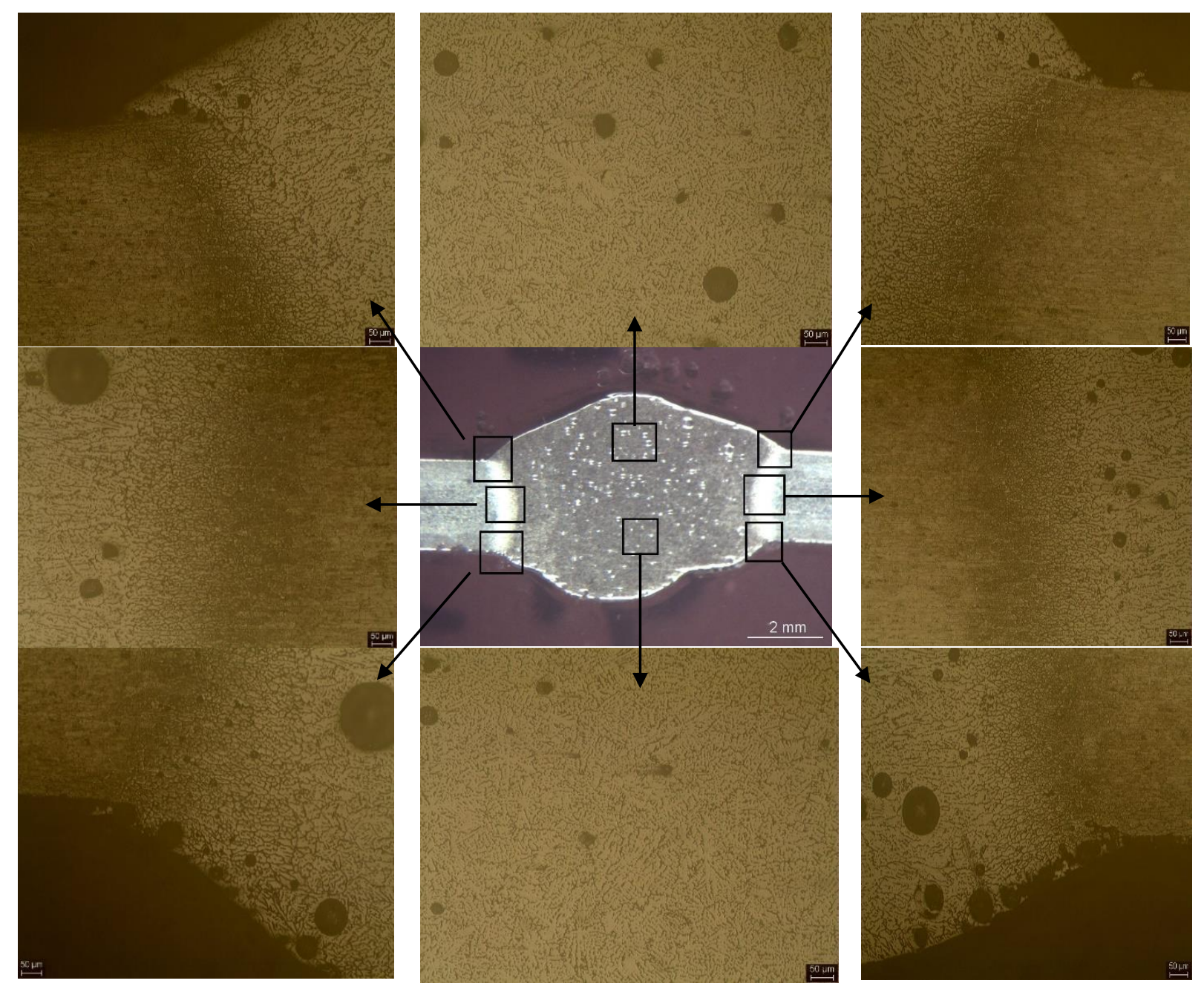

Şekil 3. Geleneksel CMT kaynaklı levhaların belirli bölgelerindeki içyapıları gösteren mikro resimler. 


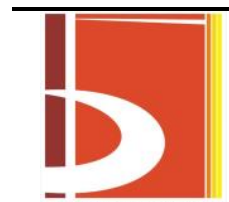

BiLLECIK ȘEYH EDEBAL UNIVERSITESI
BŞEÜ Fen Bilimleri Dergisi

7. Cilt - Milli Mücadele ve TBMM'nin

Açılışının 100. Yılı Anısına-100. Yıl Özel

Say1s1

$243-255,2020$
BSEU Journal of Science

DOI: $10.35193 /$ bseufbd. 654456

e-ISSN: 2458-7575 (http://dergipark.gov.tr/bseufbd)

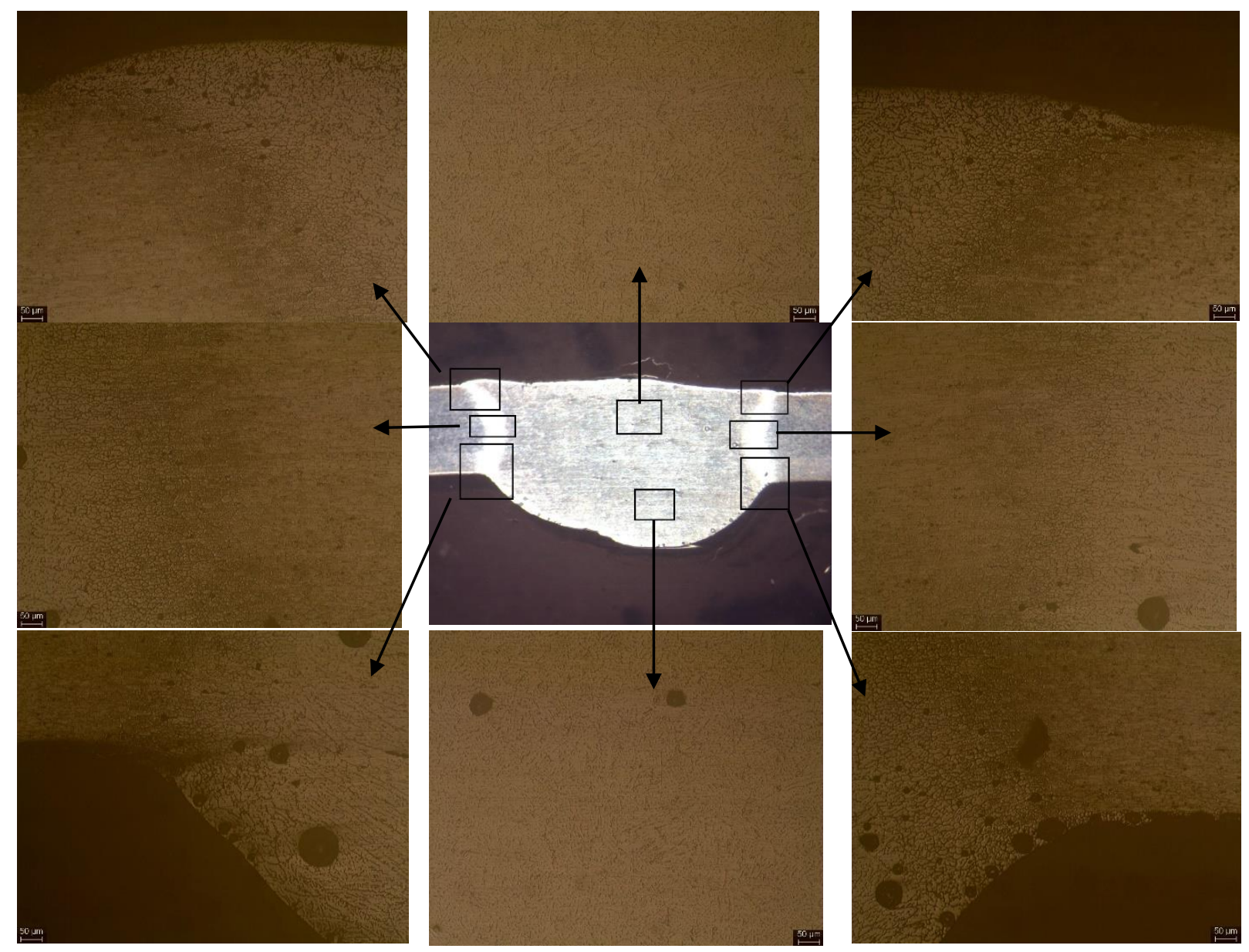

Şekil 4. Darbeli CMT kaynaklı levhaların belirli bölgelerindeki içyapıları gösteren mikro resimler.

\section{Mekanik Özellikler}

Şekil 5, elde edilen birleştirmelerin sertlik profillerini göstermektedir. Şekilden açıkça görüleceği üzere, her iki bağlantıda da, kaynak bölgesinde sertlik düşüşü meydana gelmektedir. Kaynak bölgesindeki en düşük sertlik değeri yaklaşık $65 \mathrm{HV}$ olarak ergime bölgesinde (kaynak dikişinde) gözlenmiştir. Bu durum şaşırtıcı değildir, çünkü yaşlandırma sertleştirilmesi yapılmış Al alaşımlarının ergitme kaynağında genellikle kaynak bölgesinde sertlik düşüşü meydana gelmektedir [4-7]. Ergime bölgesindeki ve ısıdan etkilenen bölgedeki sertlik kaybının nedeni sırasıyla dendritik yapı oluşumu ve mukavemet artıran çökelti partiküllerinin irileşmesidir. $\mathrm{Bu}$ çalışmada kullanılan baz plakanın temper durumu yapay olarak yaşlandııılmış haldedir (T6) ve bu temper durumundaki sertlik esas olarak alfa taneleri içindeki homojen dağılmış sertleştirici çökelti partiküllerinden kaynaklanmaktadır. $\mathrm{Bu}$ alaşım, yaşlandırma sonrası, kaynak benzeri bir işlem sırasında yüksek ısıya maruz bırakıldığında, ergime bölgesinde çökelti partiküllerinin çözülmesi ve dendritik bir yapının oluşumu ile IEB'de sertleştirici çökelti partiküllerinin irileşmesi meydana gelmektedir. Bunun sonucu, her iki bölgedeki sertlik değerlerinde bir düşüş gerçekleşmektedir. CMT ark kaynaklı AA7075-T6 plakaları için Elrefaey [33] tarafından da benzer sonuçlar rapor edilmiştir. Bu çalışmada ergime bölgesinde gözlemlenen sertlik değeri, Elrefaey tarafindan rapor edilen değerlerden biraz daha düşüktür [33].

Şekil 5' den görüleceği üzere, bu çalışmada üretilen kaynaklı bağlantılarda elde edilen sertlik profilleri, ergitme kaynaklı veya sürtünme karıştırma kaynağı ile birleştirilen AA7075-T6 alüminyum alaşımlarında 
gözlemlenen sertlik profillerinden biraz farklıdır. Sürtünme karıştırma kaynaklı AA7075-T6 alüminyum alaşımlarından elde edilen sertlik profilleri incelendiğinde $\mathrm{W}$ şeklinde bir sertlik profilinin elde edildiği görülecektir [16]. Hâlbuki bu çalışmada, elde edilen kaynak sonrası sertlik profilleri göz önüne alınırsa, en düşük sertlik değerinin kaynak dikişinde meydana geldiği görülmektedir. Kaynak işlemi esnasında bu bölgede çökelti partiküllerinin çözülmesi gerçekleşmekte ve döküm yapısına benzer dendritik bir yapı oluşmakta, bunun sonucunda en düşük sertlik değerinin bu bölgede olması genellikle karşılaşılan bir durumdur. Bu çalışmadaki bağlantıların kaynak dikişinin her iki tarafındaki aşırı yaşlanmış IEB bölgelerinde bir sertlik kaybı olmasına rağmen, burada meydana gelen sertlik kaybı, geleneksel ergitme kaynaklı veya sürtünme karıştırma kaynaklı AA7075-T6 bağlantılarının IEB bölgelerinde meydana gelen sertlik düşüşleri ile kıyaslandığında daha düşük mertebededir [16]. Öte yandan, elde edilen sertlik profilleri, düşük 1sı girdisi söz konusu olan ergitme kaynaklı (elektron ışını kaynaklı veya lazer kaynaklı) yaşlandırma sertleştirilmesi yapılmış Al-alaşımlarında rapor edilen sertlik profillerine benzemektedir [4-7].
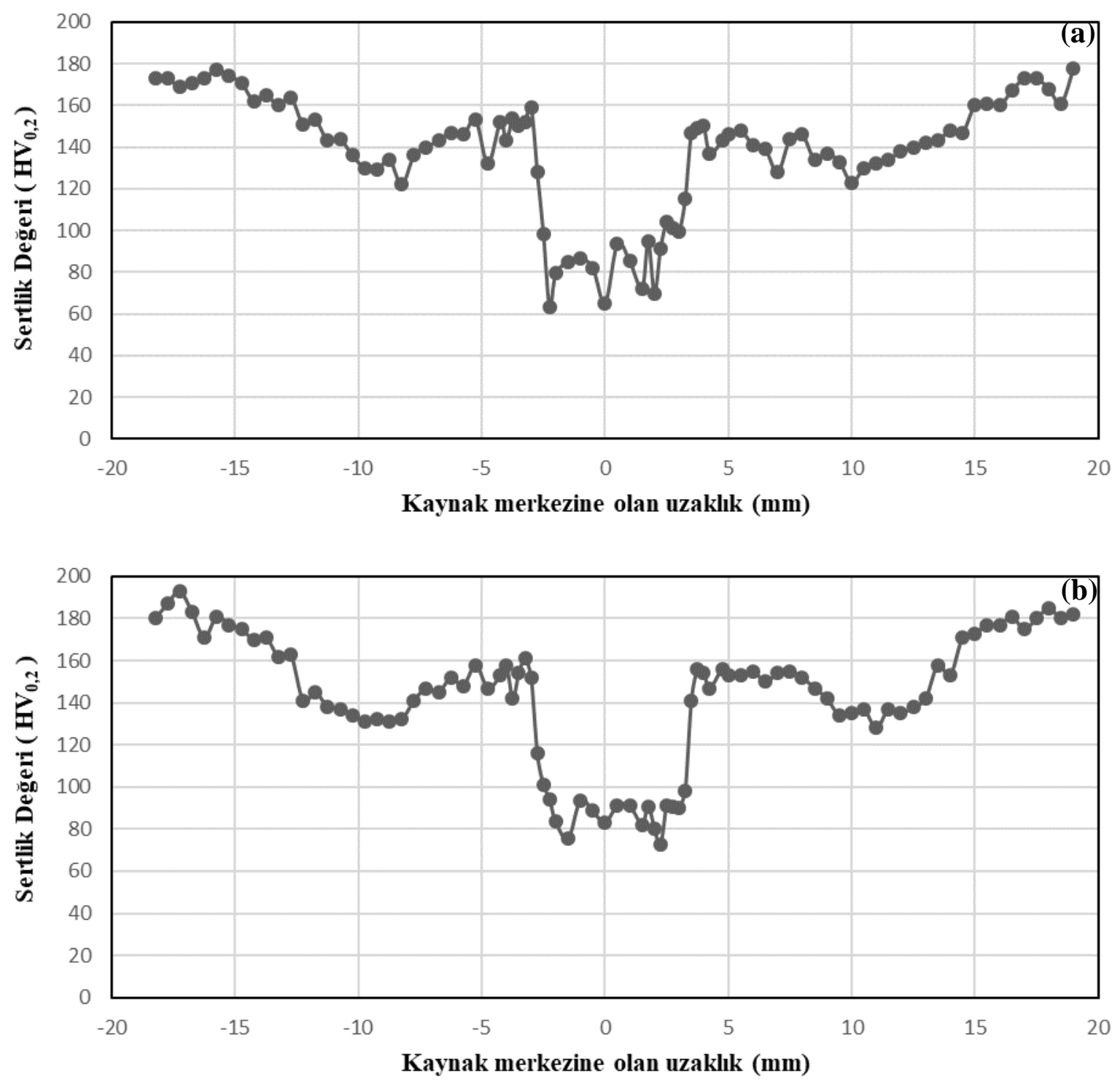

Şekil 5. Kaynaklı bağlantıların sertlik profilleri: (a) geleneksel CMT kaynaklı numune ve b) darbeli CMT kaynaklı numune. 
Çalışmada yapılan çekme deneyi sonuçları Tablo 2'de özetlenmiştir. Baz malzeme ve kaynaklı parçalardan çıkarılmış olan üç çekme testi numunesi için çekme deneyi yapılmış ve elde edilen üç sonucun ortalaması alınarak tabloda koyu karakterlerle yazılan ortalama bir çekme dayanımı değeri elde edilmiştir. Elde edilen bu ortalama çekme dayanımı değerleri yapılan kaynaklı bağlantıların mukavemet performansı değerlerini belirlemek için kullanılmıştır. Bağlantıların mukavemet performansları aşağıdaki bağıntı kullanılarak hesaplanmıştır.

Çekme Mukavemeti Performansı (\%) = (Kaynaklı Bağlantının Çekme Mukavemeti / Baz Malzemenin Çekme Mukavemeti) x 100

Tablo 2'den görüleceği üzere, elde edilen geleneksel CMT ve darbeli CMT ark kaynaklı bağlantıların mukavemet performans değerleri sırasıyla yaklaşık \%52 ve 42 olarak bulunmuştur. Bu değerler daha önce Elrefaey rapor edilen çalışmada bulunan değerden daha düşüktür (\% 60) [33]. Bunun nedeni, bu çalışmada elde edilen birleştirmelerin ergime bölgelerinde daha fazla miktarda porozite meydana gelmesidir. Ayrıca, bu çalışmada elde edilen kaynaklı birleştirmelerin ergime bölgesinde oluşan poroziteler Şekil 1'den görüleceği üzere, hem daha iri hem de oldukça büyük miktardadır. Bunun nedeni olarak da, bir önceki bölüm olan mikroyapı da tartışıldığı üzere, kaynak öncesi birleştirilecek yüzeylere uygulanan temizlik işleminin yetersizliği olarak düşünülmektedir. Bu sonuç, ayrıca Şekil 5'de verilen sertlik dağılımı ile uyumludur. Şekil 5'de görüleceği üzere, elde edilen bağlantıların ergime bölgelerinde sertlik değeri minimum olup, 65 HV civarındadır ve dolayısıyla bu bölgede baz malzeme sertlik değerine $(175 \mathrm{HV})$ oranla yaklaşık $110 \mathrm{HV}$ ' lik kayda değer bir sertlik düşüşü olmuştur. Buna ilaveten, kaynaklı plakalardan çıkarılan numunelerde elde edilen uzama değeri $\% 0.003$ gibi son derece düşüktür. Bu durum, kısmi olarak ergime bölgesinde meydana gelen mukavemet düşüşü ile alakalıdır. Ergime bölgesi içinde mukavemet, baz malzemenin mukavemetinden daha düşük olduğu için uzama sadece enine çekme testi numunelerinin kaynak bölgesi bölümünde gerçekleşir ve numunenin baz malzeme kısımlarında akma durumu gerçekleşmez (test boyunca elastik bölgededir) ve bu durumdan dolayı bu bölgelerin toplam uzamaya bir etkisi olmamaktadır. Ayrıca, kaynakı bağlantıların kaynak dikişlerindeki mukavemet düşüşü sonucu, kaynak dikişinde gerilme yoğunluğu artmakta ve kırılma düşük mukavemetin olduğu kaynaklı bölgede gerçekleşmektedir (kaynak dikişi ile sınırlı plastik şekil değiştirme sonucu), bu da süneklik seviyesinde çok büyük oranda bir düşüşe yol açmaktadır. Sadece kaynak dikişi ile sınırlı olan bu plastik şekil değiştirme olayı kaynak bölgesinde mukavemet düşüşünün meydana geldiği ergitme kaynaklı ve difüzyon kaynaklı bağlantıların birçoğunda sıklıkla karşılaşılan bir durumdur [2-7,10, 34-36]. Ayrıca, aşırı derecede düşük olan bu uzama değerinin bir diğer sebebi de Şekil 3'de görüleceği üzere, ergime bölgesinde meydana gelen iri boşlukların (porozitelerin) varlığıdır. He ve ark. [37] ortaya koyduğu gibi ergime bölgesi ile sınırlı olan bu lokal plastik deformasyon, porozitelerin varlığı söz konusu ise, porozitelerin etrafinda yoğunlaşmaktadır. Dolayısıyla, bu durum da (yani porozitelerde plastik deformasyonun yoğunlaşması) çekme numunesinin kırılmasını hızlandırmakta ve sünekliği dikkate değer oranda düşürülmektedir.

Tablo 2. Çekme deneyi sonuçları.

\begin{tabular}{|c|c|c|c|c|}
\hline Numune & $\begin{array}{l}0.2 \% \text { Akma Gerilmesi } \\
(\mathrm{MPa})\end{array}$ & $\begin{array}{l}\text { Çekme Gerilmesi } \\
\text { (MPa) }\end{array}$ & Uzama (\%) & $\begin{array}{l}\text { Çekme Gerilmesi } \\
\text { Performansı (\%) }\end{array}$ \\
\hline Baz Malzeme & $\begin{array}{l}526 ; 550 ; 541 \\
\quad(\mathbf{5 3 9})\end{array}$ & $\begin{array}{l}589 ; 605 ; 597 \\
\quad(\mathbf{5 9 7})\end{array}$ & $\begin{array}{c}14.2 ; 14.7 ; 14.9 \\
(\mathbf{1 4 , 6 )}\end{array}$ & --- \\
\hline $\begin{array}{l}\text { Geleneksel CMT kaynaklı } \\
\text { numune }\end{array}$ & --- & $\begin{array}{c}304 ; 307 ; 315 ; 323 \\
\text { (312) }\end{array}$ & $\begin{array}{c}0.002 ; 0.004 ; 0.005 ; 0.002 \\
(\mathbf{0 . 0 0 3})\end{array}$ & 52 \\
\hline $\begin{array}{c}\text { Darbeli CMT kaynaklı } \\
\text { numune }\end{array}$ & ---- & $\begin{array}{c}267 ; 263 ; 215 ; 258 \\
(\mathbf{2 5 1})\end{array}$ & $\begin{array}{c}0.004 ; 0.004 ; 0.003 ; 0.004 \\
(\mathbf{0 . 0 0 4 )}\end{array}$ & 42 \\
\hline
\end{tabular}


Kaynaklı bağlantılardan çıkarılan ve çekme deneyine tabi tutularak kırılan numuneler üzerinde kırılmanın hangi bölgede ve nasıl gerçekleştiğini belirlemek için detaylı bir metalografik çalışma yürütülmüştür. Bu çalışma sonucunda, kopmanın her iki kaynaklı levhadan çıkarılan numunelerde de ergime bölgesi içinde, ergime bölgesi ve IEB arasındaki geçiş bölgesine yakın bir yerde, meydana geldiği açık bir biçimde görülmektedir (Şekil 6). Bu durum her iki kaynaklı levhanın da, kaynak dikişinde meydana gelen mukavemet düşüşü nedeni ile hiç de şaşırtıcı değildir. Ayrıca, detaylı kırılma resimleri, çatlak ilerlemesinin ve kırılma modunun kaynak dikişinde mevcut iri poroziteler tarafından belirlendiğini ve bunun da gevrek kırılmaya yol açtığını, net bir biçimde göstermiştir. Şekil 6'dan açık bir biçimde görüleceği üzere, numunelerde kopma, çatlağın ergime bölgesi içindeki bir poroziteden diğerine geçerek poroziteler arasında köprü oluşturarak ilerlemesi sonucu ergime bölgesi içerisinde ergime bölgesi-IEB arayüzeyine yakın bir bölgede kaynak kesiti boyunca gerçekleşmiştir. Dolayısıyla bu durum, aslında ergime bölgesinin oldukça sünek (çok düşük mukavemetli) olmasına rağmen, kırılgan bir kopmaya, sonuç olarak aşırı düşük bir uzama değerine yol açmıştır.

(a)
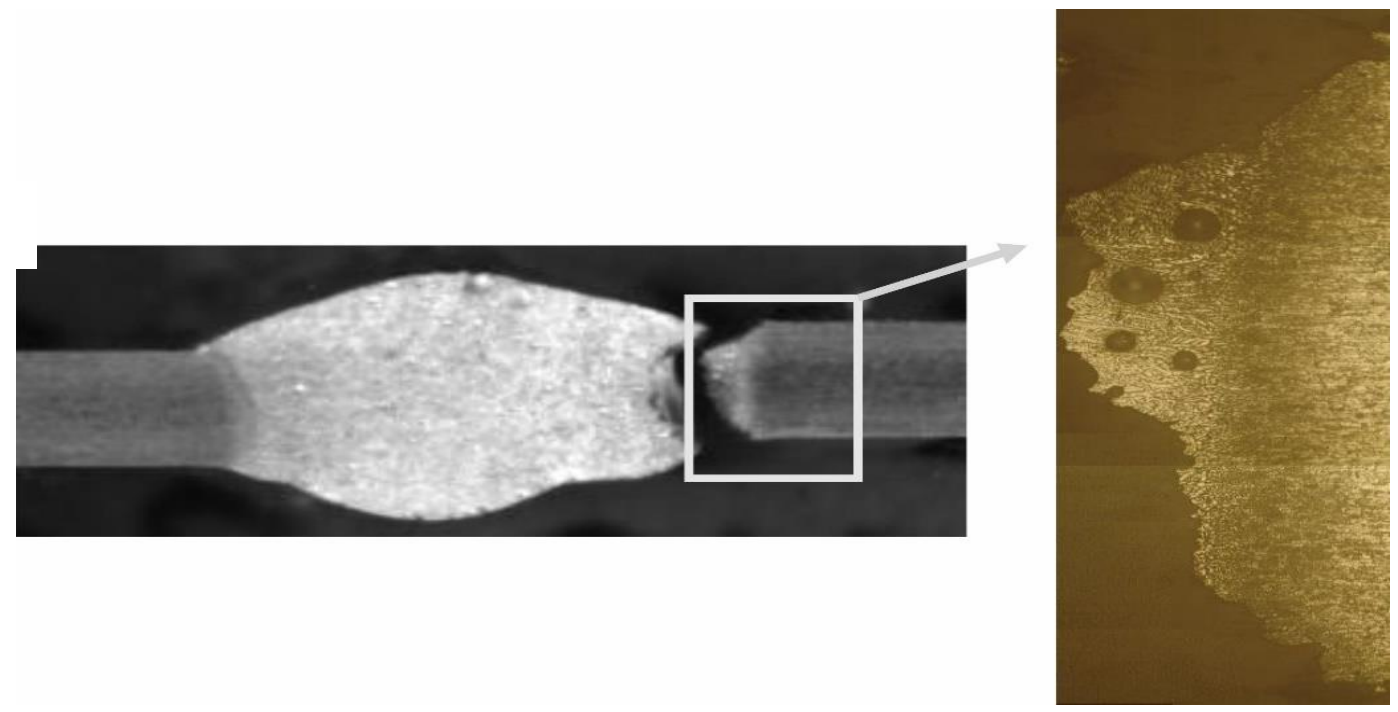

(b)

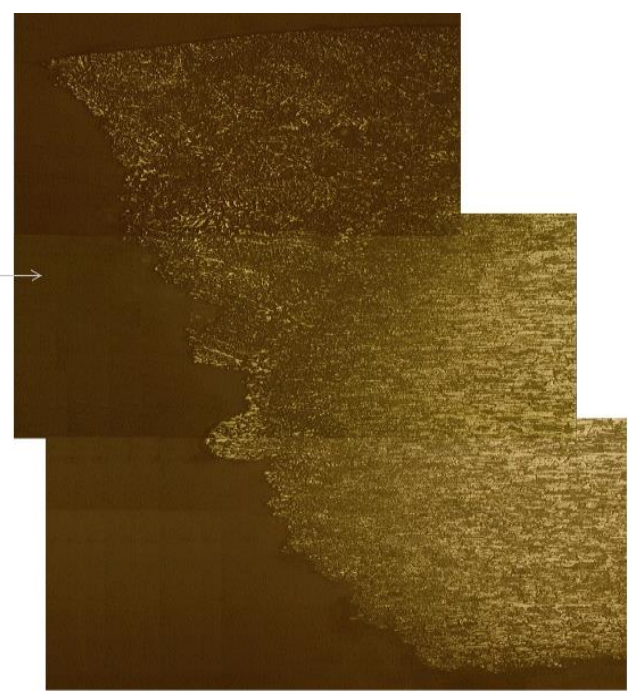

Şekil 6. Kırılma bölgelerini gösteren enine çekme deneyi numunelerinin makro resimleri ve dikdörtgen içine alınan kırılma bölgelerinin detayını gösteren daha yüksek büyütmeli mikro resimler: a) geleneksel CMT ve b) darbeli CMT. (IEB'nin yanındaki ergime bölgesi içindeki çatlak ilerlemesine ve bir boşluktan diğerine köprü yaparak meydana gelen çatlak büyümesine dikkat ediniz). 


\section{SONUÇLAR}

Bu çalışmada 2 mm kalınlığa sahip AA7075-T6 Al-alaşımı levhalar geleneksel CMT ve darbeli CMT ark kaynağı yöntemleri ile kaynak edilmiştir. Yapılan deneysel çalışmalardan elde edilen sonuçlar şunlardır:

- Geleneksel ve darbeli CMT kaynak yöntemleri kullanılarak gerçekleştirilen kaynak işlemleri sonucunda, her iki kaynak dikişinde de fazlaca büyük poroziteler içeren dendritik bir içyapı ortaya çıkmıştır. Kaynak dikişindeki bu yüksek oranda oldukça iri porozitelerin oluşmasının nedeni, kaynak öncesi kaynaklanacak levhaların yüzeylerinin yetersiz temizlenmesinden dolayıdır.

- Her iki kaynaklı levhada da en düşük sertlik dendritik içyapının gözlendiği kaynak dikişinde ölçülmüştür. Ayrıca, her iki kaynaklı levhada da kaynak dikişinin her iki tarafındaki ısıdan etkilenen bölgelerde (IEB) de sertlik düşüşü gerçekleşmiş, ancak bu sertlik düşüşü kaynak dikişine göre çok daha düşük mertebededir. Bunun geleneksel CMT ve darbeli CMT ark kaynağı yöntemlerinde söz konusu olan düşük ısı girdisi sonucu IEB'de ince taneli bir içyapı oluşumu ve mukavemetlendirici partiküllerin aşırı kabalaşmaması olduğu düşünülmektedir.

- Her iki kaynaklı levhada da çekme deneyi numuneleri kaynak dikişi içerisinde ve IEB'ye yakın kısımda kırılmıştır ve bu en düşük sertlik değerinin kaynak dikişinde olduğu kaynaklı levhaların sertlik profilleri ile uyumludur.

- Geleneksel CMT ve darbeli CMT ark kaynaklı levhaların çekme mukavemeti performanslarının düşük olduğu (sırasıyla yaklaşık \%52 ve \%42 civarında) ve bu düşük çekme mukavemeti performanslarının hem kaynak dikişinde sertliğin en düşük olması hem de büyük oranda porozite olmasından kaynaklanmaktadır.

- Her iki kaynaklı levha da oldukça düşük süneklik performansı değeri göstermiştir. Bu çok düşük süneklik performansı değerlerinin iki nedeni bulunmaktadır. Bunlardan ilki her iki kaynaklı levhanın da kaynak dikişinde sertliğin en düşük olması sonucu çekme deneyinde numunenin sadece kaynak dikişi bölgesinin plastik şekil değiştirmesidir. İkinci neden ise her iki kaynaklı levhanın kaynak dikişinde büyük ve çok sayıda mevcut porozitenin plastik deformasyonun lokal olarak porozite bölgelerinde yoğunlaşması sonucu kırılmayı hızlandırmasıdır.

- Ayrıca, kaynak dikişinde çatlağın mevcut çok sayıda birbirine yakın büyük poroziteler üzerinden ilerlemesi sonucu porozitelerin çatlak ilerlemesini dikte ettiği, kırılma modunu belirlediği ve gevrek kırılmaya yol açtığı gözlenmiştir.

\section{KAYNAKLAR}

[1] Anderson, T. (2010). Welding Aluminium - Questions and Answers: A practical guide for troubleshooting aluminum welding-related problems 2nd edition, American Welding Society, FL, USA, 1-9.

[2] Çam, G. \& İpekoğlu, G. (2017). Recent developments in joining of aluminum alloys. The International Journal of Advanced Manufacturing Technology, 91, 1851-1866.

[3] Kashaev, N., Ventzke, V. \& Çam, G. (2018). Prospects of laser beam welding and friction stir welding processes for aluminum airframe structural applications. Journal of Manufacturing Processes, 36, 571-600.

[4] Pakdil, M., Çam, G., Koçak, M. \& S. Erim, (2011) Microstructural and mechanical characterization of laser beam welded AA6056 Al-alloy. Materials Science and Engineering: A, 528, 7350-7356.

[5] Çam, G. \& Koçak, M. (2007). Microstructural and mechanical characterization of electron beam welded Al-alloy 7020", Journal of Materials Science, 42, 7154-7161.

[6] Çam, G., Ventzke, V. \& dos Santos, J. (1999). Characterization of laser and electron beam welded Alalloys. Praktische Metallographie, 36 (2), 59-89. 
[7] Çam G., Ventzke, V., dos Santos, J., Koçak, M., Jennequin, G. \& Gonthier-Maurin, P. (1999). Characterisation of electron beam welded aluminium alloys. Science and Technology of Welding and Joining, 4, 317-323.

[8] Çam, G. \& Mistıkoğlu, S. (2014). Recent developments in friction stir welding of Al-alloys. Journal of Materials Engineering and Performance, 23, 1936-1953.

[9] Çam, G., Güçlüer, S., Çakan, A. \& Serindağ H.T. (2009). Mechanical properties of friction stir butt-welded Al-5086 H32 plate. Materialwissenschaft und Werkstofftechnik, 40, 638-642.

[10] Çam, G. (2005). Sürtünme Karıştırma Kaynağı. (SKK): Al-Alaşımları İçin Geliştirilmiş Yeni. Bir Kaynak Teknolojisi', Mühendis ve Makine (Engineer and Machinery), 46, 30-39.

[11] Von Strombeck, A., Cam, G., dos Santos, J. F., Venzke, V. \& Kocak, M. (2001). A Comparison Between Microstructure, Properties, and Toughness Behavior of Power Beam and Friction StirWelds in Al-Alloys, The TMS 2001 Annual Meeting Aluminum, Automotive and Joining, February 12-14, Warrendale, PA, 49264.

[12] dos Santos, J. F., Çam, G., Torster, F., Insfran, A., Riekehr, S., Ventzke, V. \& Koçak, M. (2000). Properties of power beam welded steel, Al-and Ti alloys: Significance of strength mismatch", Welding in the World, $44,42-64$.

[13] İpekoğlu, G., Kıral B. G., Erim, S. \& Çam, G. (2012). Investigation of the effect of temper condition on friction stir weldability of AA7075 Al-alloy plates. Materiali in tehnologije, 46, 627-632.

[14] İpekoğlu, G., Erim, S., Kıral, B. G. \& Çam, G. (2013). Investigation into the effect of temper condition on friction stir weldability of AA6061 Al-alloy plates", Kovové materiály, 51, 155-163.

[15] G. İpekoğlu, Erim, S., \& Çam, G. (2014). Investigation into the influence of post-weld heat treatment on the friction stir welded AA6061 Al-alloy plates with different temper conditions, Metallurgical and Materials Transactions A, 45, 864-877.

[16] İpekoğlu, G., Erim, S. \& Çam, G. (2014). Effects of temper condition and post weld heat treatment on the microstructure and mechanical properties of friction stir butt welded AA7075 Al-alloy plates. The International Journal of Advanced Manufacturing Technology, 70, 201-213.

[17] İpekoğlu, G. \& Çam, G. (2014). Effects of initial temper condition and postweld heat treatment on the properties of dissimilar friction-stir-welded joints between AA7075 and AA6061 aluminum alloys. Metallurgical and Materials Transactions A, 45, 3074-3087.

[18] Çam, G., İpekoğlu, G. \& Serindağ, H. T. (2014). Effects of use of higher strength interlayer and external cooling on properties of friction stir welded AA6061-T6 joints. Science and Technology of Welding and Joining, 19, 715-720.

[19] Bozkurt, Y., Salman, S. \& Çam, G. (2013). The effect of welding parameters on lap-shear tensile properties of dissimilar friction stir spot welded AA5754-H22/2024-T3 joints. Science and Technology of Welding and Joining, 18, 337-345.

[20] Çam, G. (2001). Al-Alaşımları İçin Geliştirilen Yeni Kaynak Yöntemleri. TMMOB Makina Mühendisleri Odas1, Kaynak Teknolojisi III. Ulusal Kongresi, 19-20 Ekim, İstanbul, 267-277.

[21] Günen A., Kanca, E., Demir, M., Cavdar, F., Mistikoglu, S. \& Cam, G. (2018). Microstructural and mechanical properties of friction stir welded pure lead. Indian Journal Of Engineering and Materials Sciences, 25, 26-32. 
[22] Küçükömeroğlu, T., Şentürk, E., Kara, L, İpekoğlu, G. \& Çam, G. (2016). Microstructural and mechanical properties of friction stir welded nickel-aluminum bronze (NAB) alloy. Journal of Materials Engineering and Performance, 25, 320-326.

[23] Çam, G. (2011). Friction stir welded structural materials: Beyond Al-alloys. International Materials Reviews, 56(1), 1-48.

[24] Çam, G., İpekoğlu, G., Küçükömeroğlu, T. \& Aktarer S.M. (2017). Applicability of friction stir welding to steels. Journal of Achievements in Materials and Manufacturing Engineering, 80, 65-85.

[25] Çam G., Ventzke, V., dos Santos, J., Koçak, M., Jennequin, G. \& Gonthier-Maurin, P. (1999). Characterisation of electron beam welded aluminium alloys. Science and Technology of Welding and Joining, 4, 317-323.

[26] Küçükömeroğlu, T., Aktarer, S.M., İpekoğlu, G. \& Çam, G. (2018). Mechanical properties of friction stir welded St 37 and St 44 steel joints. Materials Testing, 60, 1163-1170.

[27] Küçükömeroğlu, T., Aktarer, S.M., İpekoğlu, G. \& G. Çam, "Microstructure and mechanical properties of friction stir welded St52 steel joints”, International Journal of Minerals, Metallurgy and Materials, 25, 1457-1464.

[28] Selvi, S., Vishvaksenan, A. \& Rajasekar, E. (2018). Cold metal transfer (CMT) technology - An overview. Defence Technology, 14, 28-44.

[29] Pickin, C.G. \& Young, K. (2006). Evaluation of cold metal transfer (CMT) process for welding aluminium alloy. Science and Technology of Welding and Joining, 11, 583-585.

[30] Cornacchia, G., Cecchel, S. \& Panvini, A. (2018). A comparative study of mechanical properties of metal inert gas (MIG)-cold metal transfer (CMT) and fiber laser-MIG hybrid welds for 6005A T6 extruded sheet. The International Journal of Advanced Manufacturing Technology, 94, 2017-2030.

[31] Gungor, B., Kaluc, E., Taban, E. \& Ş1k, A. (2014). Mechanical and microstructural properties of robotic cold metal Trasfer (CMT) welded 5083-H111 and 6082-T\&51 aluminum alloys, Materials \& Design, 54, 207-211.

[32] Cong, B., Ding, J. \& Williams, S. (2015). Effect of arc mode in cold metal transfer process on porosity of additively manufactured $\mathrm{Al}-6.3 \% \mathrm{Cu}$ alloy. The International Journal of Advanced Manufacturing Technology, 76, 1593-1606.

[33] Elrefaey, A. (2015). Effectiveness of cold metal transfer process for welding 7075 aluminium alloys. Science and Technology of Welding and Joining, 20, 280-285.

[34] Koçak, M., Pakdil, M. \& Çam, G. (2002). Fracture behaviour of diffusion bonded Ti-alloys with strength mismatch. Science and Technology of Welding and Joining, 7, 187-196.

[35] Çam, G., Koçak, M., Dobi, D., Heikinheimo, L. \& Siren, M. (1997). Fracture behaviour of diffusion bonded bimaterial Ti-Al joints. Science and Technology of Welding and Joining, 2(3), 95-101.

[36] İpekoğlu G., Akçam, Ö. \& Çam, G. (2018). Effect of plate thickness on weld speed in friction stir welding of AA6061-T6 Al-alloy plates. The Paton Welding Journal, 12, 77-82.

[37] He, E., Liu, J., Lee, J., Wang, K., Politis, D.J., Li, C. \& Wang, L. (2018). Effect of porosities on tensile properties of laser-welded Al-Li alloy: an experimental and modelling study", The International Journal of Advanced Manufacturing Technology, 95, 659-671. 